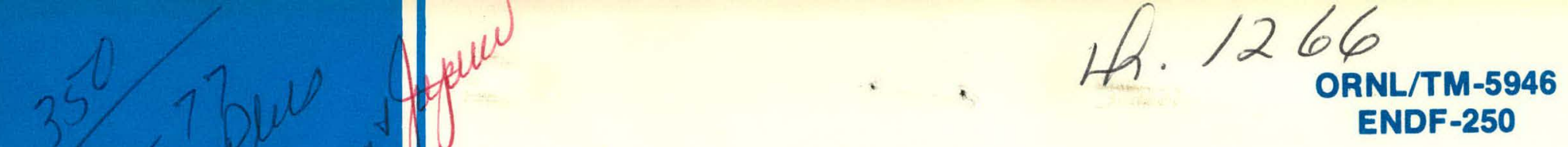

\title{
Sendin and Sentinel: Two Computer Codes to Assess the Effects of Nuclear Data Changes
}

\author{
J. H. Marable \\ J. D. Drischler \\ C. R. Weisbin
}




\section{DISCLAIMER}

This report was prepared as an account of work sponsored by an agency of the United States Government. Neither the United States Government nor any agency Thereof, nor any of their employees, makes any warranty, express or implied, or assumes any legal liability or responsibility for the accuracy, completeness, or usefulness of any information, apparatus, product, or process disclosed, or represents that its use would not infringe privately owned rights. Reference herein to any specific commercial product, process, or service by trade name, trademark, manufacturer, or otherwise does not necessarily constitute or imply its endorsement, recommendation, or favoring by the United States Government or any agency thereof. The views and opinions of authors expressed herein do not necessarily state or reflect those of the United States Government or any agency thereof. 


\section{DISCLAIMER}

Portions of this document may be illegible in electronic image products. Images are produced from the best available original document. 


\section{Printed in the United States of America. Available from National Technical Information Service \\ U.S. Department of Commerce 5285 Port Royal Road, Springfield, Virginia 22161 \\ Price: Printed Copy $\$ 4.00 ;$ Microfiche $\$ 3.00$}

This report was prepared as an account of work sponsored by the United States Government. Neither the United States nor the Energy Research and Development Administration/United States Nuclear Regulatory Commission, nor any of their employees, nor any of their contractors, subcontractors, or their employees, makes any warranty, express or implied, or assumes any legal liability or responsibility for the accuracy, completeness or usefulness of any information, apparatus, product or process disclosed, or represents that its use would not infringe privately owned rights. 
Contract No. W-7405-eng-26

Neutron Physics Division

SENDIN AND SENTINEL: TWO COMPUTER CODES

TO ASSESS THE EFFECTS OF NUCLEAR DATA CHANGES

J. H. Marable, J. D. Drischler, and C. R. Weisbin

Date Published: July 1977

Prepared by the

OAK RIDGE' NATIONAL LABORATORY

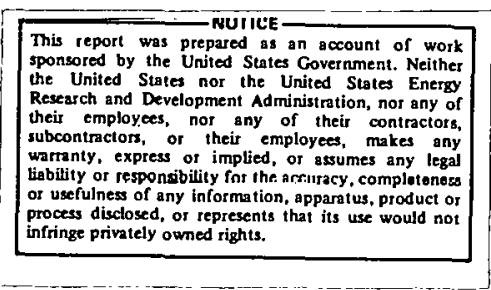

Oak Ridge, Tennessee 37830

operated by

UNION CARBIDE CORPORATION

for the

ENERGY RESEARCH AND DEVELOPMENT ADMINISTRATION 
THIS PAGE

\section{WAS INTENTIONALLY \\ LEFT BLANK}


TABLE OF CONTENTS

Page

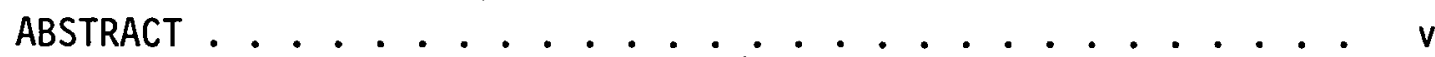

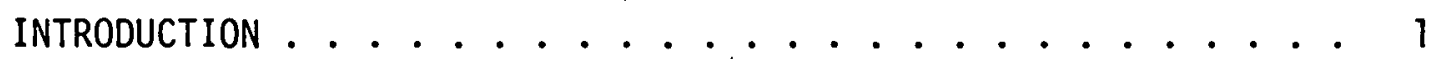

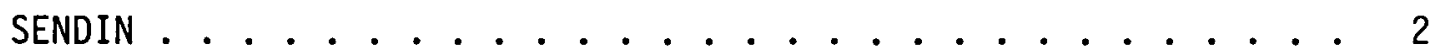

Sample Problem for SENDIN............. 3

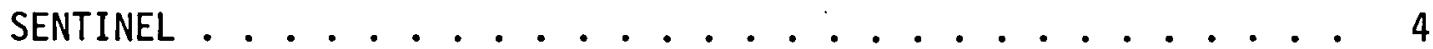

Sample Problem for SENTINEL . . . . . . . . . 7



APPENDIX A. The Format for Standard Interface File SENPRO

for Group-Dependent Sensitivity Coefficients . . . 11

APPENDIX B. The FIDO Input System . . . . . . . . . . 17 
THIS PAGE

\section{WAS INTENTIONALLY \\ LEFT BLANK}




\section{ABSTRACT}

A description is given of the computer code SENTINEL, which provides a simple means for finding the effects on calculated reactor and shielding performance parameters due to proposed changes in the cross section data base. This code uses predetermined detailed sensitivity coefficients in SENPRO format, which is described in Appendix A. Knowledge of details of the particular reactor and/or shielding assemblies is not required of the user. Also described is the computer code SENDIN, which converts unformatted (binary) sensitivity files to card image form and vice versa. This is useful for transferring sensitivity files from one installation to another. 


\section{INTRODUCTION}

Sensitivity coefficients for performance parameters of reactor and shielding systems, ${ }^{1}$ especially benchmarks, have been collected in an interface file $e^{2}$ using the SENPRO format. This format was developed according to the standards established by the Committee on Computer Codes Coordination (CCCC). ${ }^{3}$ The description of the SENPRO format is given in Appendix A.

In order to use the sensitivity data on a file, it is necessary to have codes which can read such files as well as to perform the required computational manipulations. Such files are ordinarily unformatted (binary) for computational efficiency, but are not easily read on a different type of computer. To facilitate the transfer of data from one installation to another, the data are converted to card image form. This requires a code which can translate a binary file to card image form and vice versa.

This report documents two codes. The first, SENDIN, is useful for converting a sensitivity file from binary to card image, for converting from card image to binary, and for obtaining a printed listing of a sensitivity file. The second, SENTINEL, calculates the percent change in a specified response due to given percent changes in specified reaction cross sections over specified energy regions. An edited list of the most significant individual contributions to the response change is also given. 
SENDIN

The program SENDIN copies a sensitivity file in SENPRO format, and in the copying process changes the file representation from binary to card image form or vice versa. In addition, a complete listing or a partial listing of the file is printed to give the user accurate information about the contents of a particular file.

There are two (2) input files:

(1) The SENPRO sensitivity file to be converted and which is specified by the FORTRAN data-set reference number NIN (default value 20 ).

(2) The control file which consists of a single card (card image) and which is specified by FORTRAN data-set reference number 5 . This card consists of four integers in (4I5) format: NBE, NIN, NøUT, Nø6.

NBE $=0$ conversion is binary to card image.

$\neq 0$ conversion is card image to binary.

NIN = FORTRAN data-set reference number of the input sensitivity filc to be converted (a zern or negative value is replaced by the defauit value of 20 ).

NQUT = FORTRAN dald-set reference number of the converted output file of sensitivities (a zero or negative value is replaced by a default value of 21 ).

Nø6 specifies the printer output FORTRAN data-set reference number and the type of edit - complete or reduced (a zero value of $N \emptyset 6$ is replaced by the default value of -6$)$. 
$N \emptyset 6>0$ an edit of the entire file is formed on the unit with FORTRAN data-set reference number $N 96$.

$N \oslash 6<0$ a reduced edit of the file is formed on the unit with FORTRAN data-set reference number -N@6.

There are two output files (both referred to above):

(1) The converted sensitivity file with data-set reference number NøUT (default value 21 ).

(2) The file of printer output with data-set reference number specified by Nø6 (default value 6 ).

\section{Sample Problem for SENDIN:}

The input on unit 5 consists of a single blank card. Unit 20 contains the binary SENPRO file. On unit 21 is a dummy file.

$/ / G \emptyset . F T 20 F 001$ DD DSN= etc., UNIT= etc.

$/ / G D . F T 21 F 001$ DD DUMMY

$/ / G \emptyset$. FT05F001 DD *

(1 blank card)

$/ *$

The blank card could be replaced by the following:

$$
\begin{array}{llll}
0 & 20 & 21 & -6
\end{array}
$$

with the same result:

The printer output on unit 6 produces a reduced edit of the SENPRO file on unit 20 . 


\section{SENTINEL}

The program SENTINEL computes the percentage (or fractional) change in the performance parameter of a given assembly due to specified percentage (or fractional) changes in designated reaction cross sections over a number of energy regions.

The input data consists of:

(1) Parameters defining the performance parameter. the reactor or assembly, the number $N$ of such sensitivities to be included, and the identification for these so that they may be selected from the sensitivity file which is in SENPRO format.

(2) The number of energy regions KMAX and the energy bounds for each such region.

(3) The percentage (or fractional) change in nuclear data for each of the $N$ reactions for which a sensitivity is specified by (1) above, and over each of the KMAX energy regions specitied in (2).

(4) Certain information specifying the printer output data-set reference number (default value 6), and the SENPRO sensitivity file data-set reference number (default value 10).

(5) Information limiting the printout of the most important individual contributions to the resulting change in the performance parameter.

(6) The binary sensitivity file in SENPRO format.

The output consists of:

(1) The input information.

(2) Information selected from the sensitivity file. 
(3) The resulting value of the percentage (or fractional) change in the performance parameter.

(4) An ordered list of the most important individual contributions to the change.

Specifically, the input to SENTINEL for one case consists of one card of six numbers and three arrays entered in FIDO system format. The FIDO system is described in Appendix B. Several stacked cases can be calculated in one run. The following input is required for each case:

one card (format 2I5, F10, 3I5): $\quad$ N, KMAX, PERCNT, NUMB, LUNIT, I array of energy regions:

$$
1 \text { 1** ((EHI (K),EL } \emptyset(K)), K=1, K M A X)
$$

percent changes:

$3^{\star \star}((\operatorname{PRCENT}(K, N 1), K=1, K M A X), N 1=1, N)$

sensitivity identifiers: $5 \$ \$((\operatorname{INF} \emptyset(I, N 1), I=1,9), N]=1, N)$

FID $\emptyset$ terminator:

$N=$ the number of sensitivity profiles to be included.

KMAX = the number of energy regions to be included.

PERCNT = the minimum magnitude (in percent of the total contribution) of a single (one energy region and one reaction) contribution to be included in a printout of the most important individual contributions.

NUMB $=$ the maximum number of most important contributions to be printed out individually.

LUNIT = the data set reference number of the sensitivity file in SENPRO format (default value $=10$ ). IØUT $=$ printer output data-set reference number (default value $=6$ ). 
$\mathrm{EHI}(\mathrm{K})=$ an energy bound in eV for energy region $K$ (the regions should appear in order of decreasing energy). $E L \emptyset(K)=$ the other bound for region $K$. $\operatorname{PRCENT}(K, N 1)=$ the percent change in nuclear data associated with sensitivity $\mathrm{N} 1$ in energy region $K$.

INFØ ( $I, N 1) \quad I=1,9$ consists of nine identifiers for the sensitivity profile N1. The nine identifiers in order are:

IASB = the assembly identifier as it appears in the file, or, if the first $\operatorname{IASB}(=\operatorname{INF} \emptyset(1,1))$ is negative, cases are made to include every assembly in the file.

IRESP $=1,2,3,4,5$ according as the response is multiplication factor $k$, breeding ratio, worth, reaction rate ratio, or some other type of response, respectively; or, if the first $\operatorname{IRESP}(=\operatorname{INFD}(2,1))$ is negative, cases are made to include all responses.

MATID = nuclide identification using ENDF assignments.

MT = reaction identification using ENDF assignments .

NTRN $=1,2,3, \ldots$ an arbitrary identification number chosen by the file creator to distinguish different reaction rate or worth responses ( 0 for IRESP $=1$ ).

ITYPE, IZØN1, IZØN2, ISCAT refer to partial sensitivities and are set to zero since no partial sensitivities are presently used. 
Sample Problem for SENTINEL:

This problem determines the effect of proposed changes in the fission cross section (MT number 18) of $235 \mathrm{U}, 238 \mathrm{U}$, and $239 \mathrm{Pu}$ (MAT numbers 1261 , 1262, and 1264 respectively) on the multiplication factor (IRESP $=1$ and NTRN=0) of each assembly in the file (five), and on the central reaction rate ratio ${ }^{28} \mathrm{c} /{ }^{49} \mathrm{f}$ (IRESP $=4$ and $N T R N=1$ ), and on the central reaction rate ratio ${ }^{28} f /{ }^{49} f(I R E S P=4$ and $N T R N=2)$ of the $Z P R-6 / 7$ assembily. (IASB $=5$ is the number assigned this assembly in the SENPRO file reported in Ref. 2.) The proposed changes represent approximate. changes in going from ENDF/B-IV to ENDF/B-V. These changes are given in five groups as follows:

\begin{tabular}{ccccc}
$\begin{array}{c}\text { Energy Range } \\
\text { (MeV) }\end{array}$ & $\begin{array}{c}\text { Change in } \sigma_{f}^{25} \\
\text { (percent) }\end{array}$ & $\begin{array}{c}\text { Change in } \sigma_{f}^{28} \\
\text { (percent) }\end{array}$ & $\begin{array}{c}\text { Change in } \sigma_{f}^{49} \\
\text { (percent }\end{array}$ \\
\cline { 1 - 1 } $3.679-10.000$ & 1.44 & -2.50 & -1.07 \\
$1.353-3.679$ & -0.24 & & -3.50 & 0.83 \\
$.498-1.353$ & -2.57 & 12.00 & 1.02 \\
$.183-.498$ & -3.32 & 0.00 & -0.30 \\
$.067-.183$ & -2.13 & 0.00 & -2.13
\end{tabular}

This sample problem uses the fast benchmarks for which sensitivities are reported in reference 2 . We assume these sensitivities are available in binary SENPRO format on a unit with data-set reference number 10.

The input can be stacked as three cases. The first searches through all the assemblies in the file (since $\operatorname{INFO}(1,1)$ is negative) and manufactures a case for each assembly found. For these we limit to ten (NUMB $=10$ ) the number of individual largest contributions to be printed out, regardless of magnitude. 
The second of the three input cases finds the change in the central reaction-rate ratio ${ }^{28} \mathrm{C} /{ }^{49} \mathrm{f}$ in $\mathrm{ZPR}-6 / 7$ and prints out the largest individual contributions, each of which is not less than one percent (PERCNT $=1.0)$ of the total calculated change. Not more than five such contributions will be printed out.

The third input case calculates the resulting change in the ${ }^{28} \mathrm{c} / /^{49} \mathrm{f}$ ratio in ZPR-6/7 and prints out (not more than six) individual contributions greater than four percent of the total.

The input data files are as follows:

$/ / G \emptyset . F T 10 F 001$ DD DSN=etc. ,UNIT=VQL= etc.

$/ / G D . F T 05 F 001$ DD A



The output prints a warning message to note whenever a sensitivity is missing in the file and, hence, is not included in the calculation. Note that since the dimensions $\mathrm{N}$ and KMAX are constant the order of the reactions (MAT-MT pairs) remains fixed and that the energy regions ( ${ }^{\star \star}$ array) and the assigned percentages (3** array) remain fixed in storage location as well as in value. Therefore, the FIDO 1 ** and $3^{* *}$ arrays need not be read in again after the first case. 


\section{REFERENCES}

1. C. R. Weisbin, J. H. Marable, J. L. Lucius, E. M. Oblow, F. R. Mynatt, R. W. Peelle, and F. G. Perey, "Application of FORSS Sensitivity and Uncertainty Methodology to Fast Reactor Benchmark Analysis," ORNL/TM-5563 (1976).

2. J. H. Marable, J. L. Lucius, and C. R. Weisbin, "Compilation of Sensitivity Profiles for Several CSEWG Fast Reactor Benchmarks," Oak Ridge National Laboratory report ORNL-5262 (ENDF-234) (March 1977).

3. B. M. Carmichael, "Standard Interface Files and Procedures for Reactor Physics Codes, Version III," Los Alamos Scientific Laboratory report LA-5486-MS (February 1974). 
THIS PAGE

\section{WAS INTENTIONALLY LEFT BLANK}


APPENDIX A

The Format for Standard Interface File SENPRO for Group-Dependent Sensitivity Coefficients 


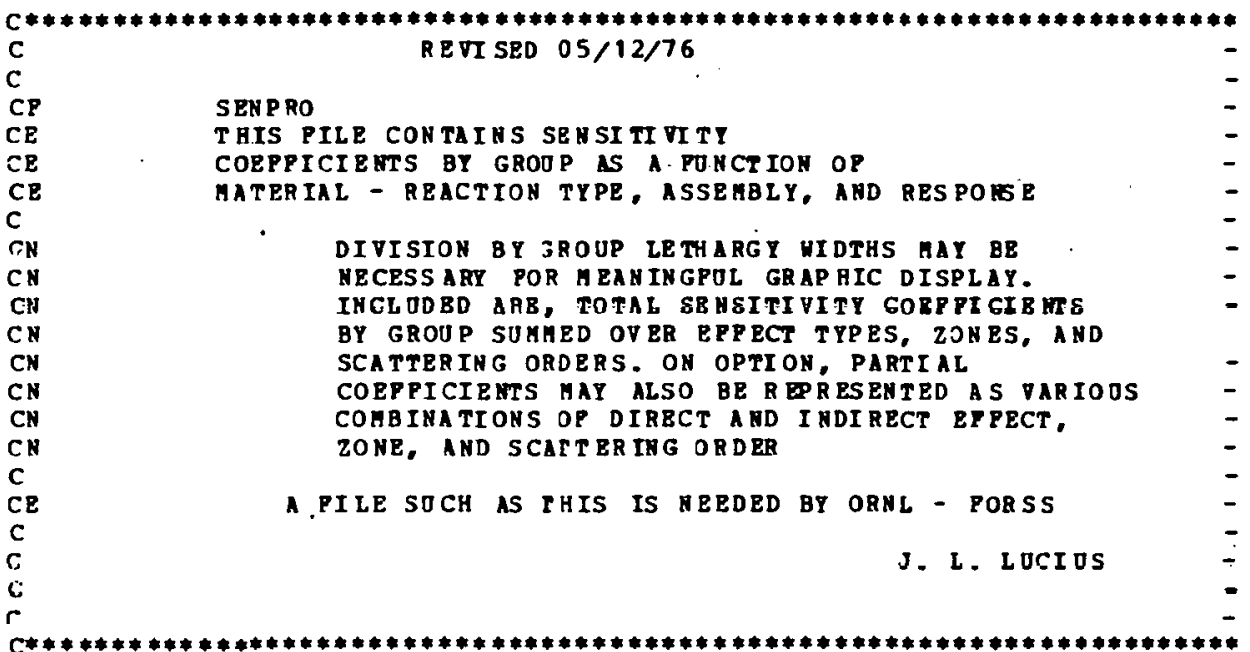

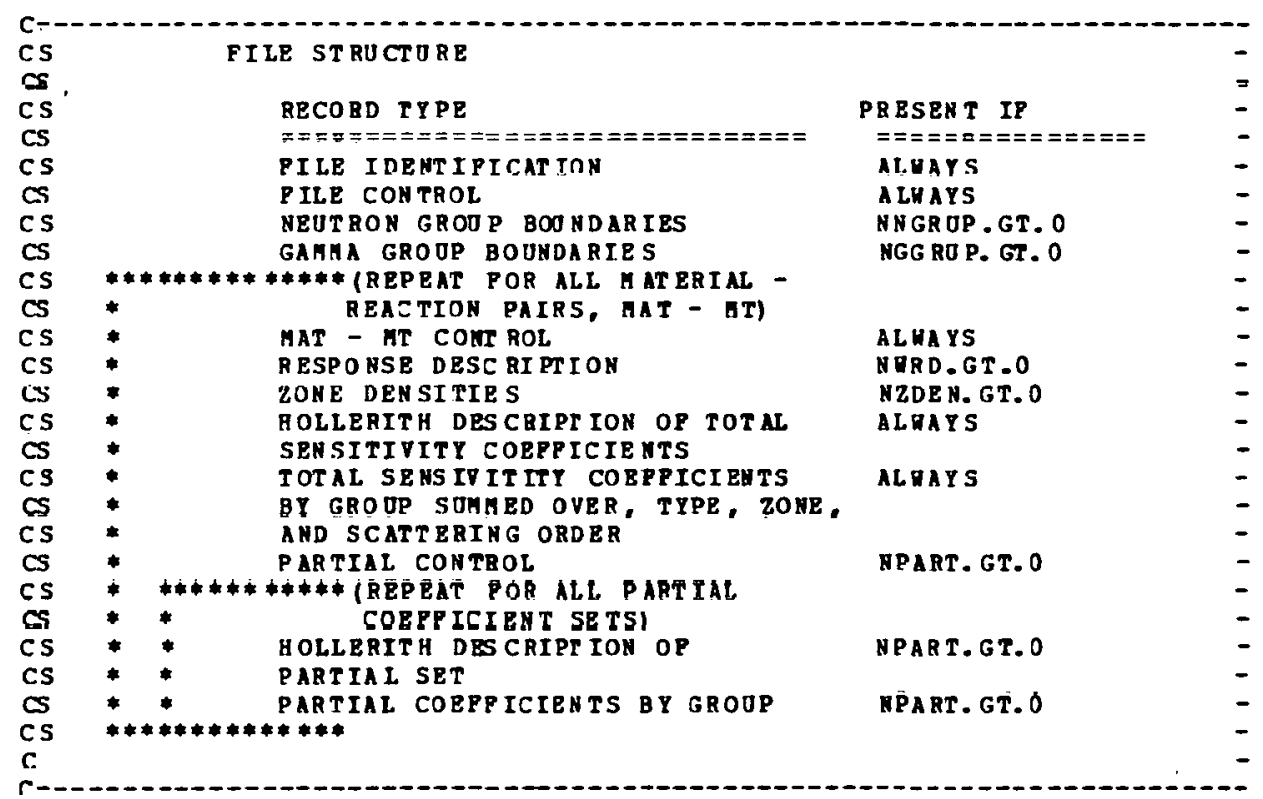

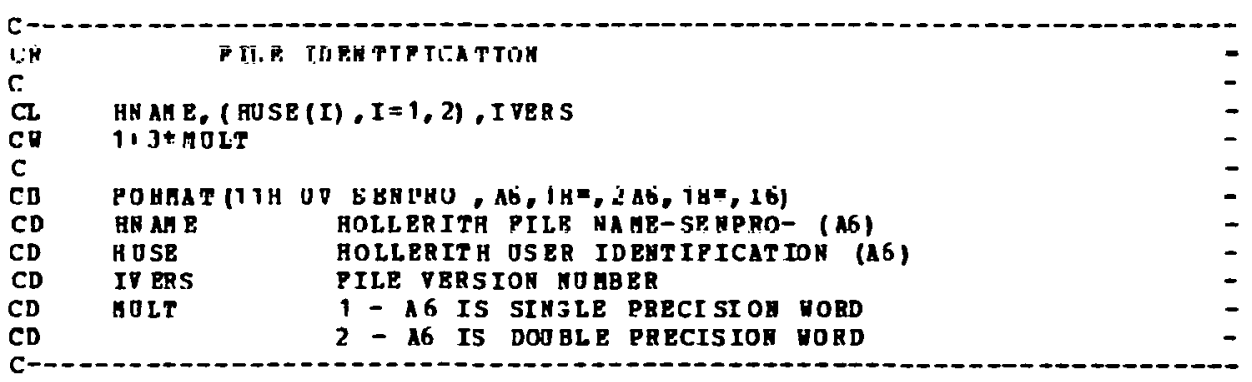




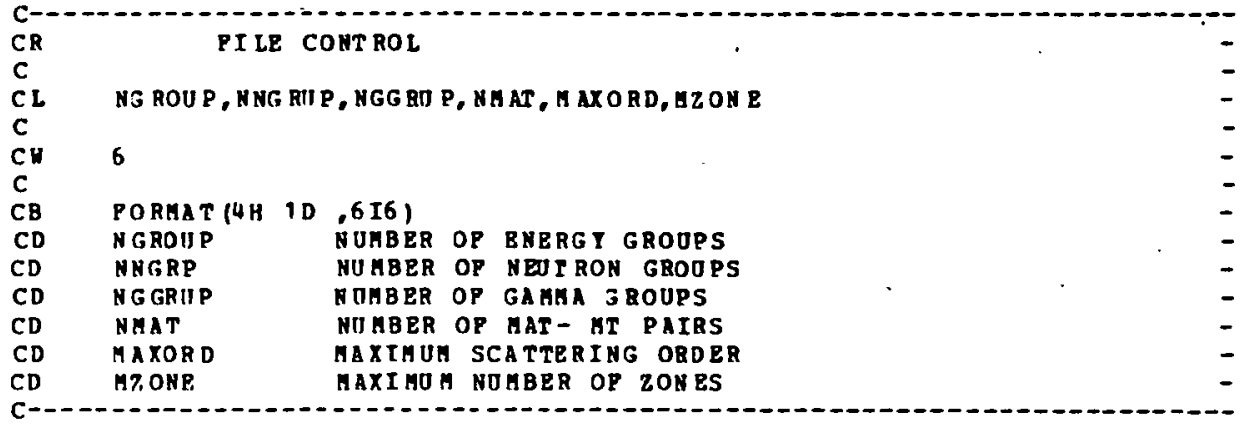

CR
$C$
$C L$
$C$
$C C$

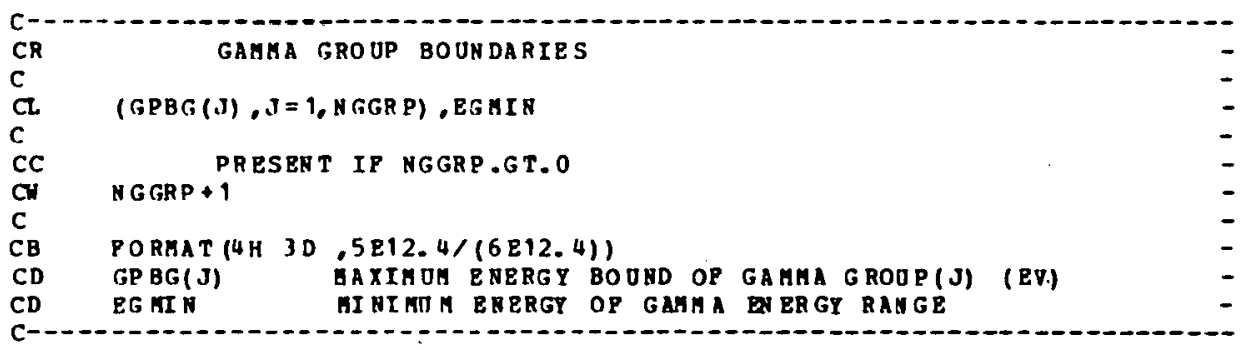

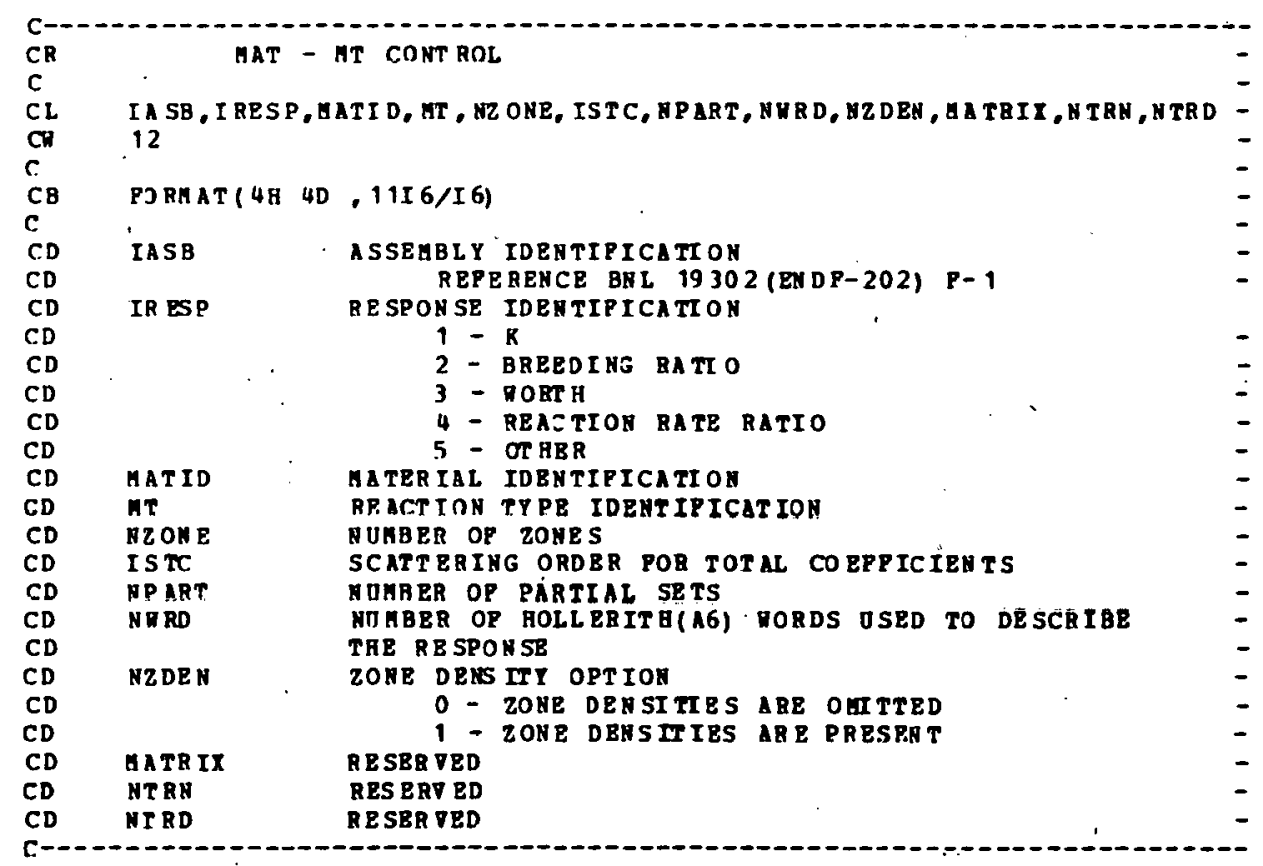



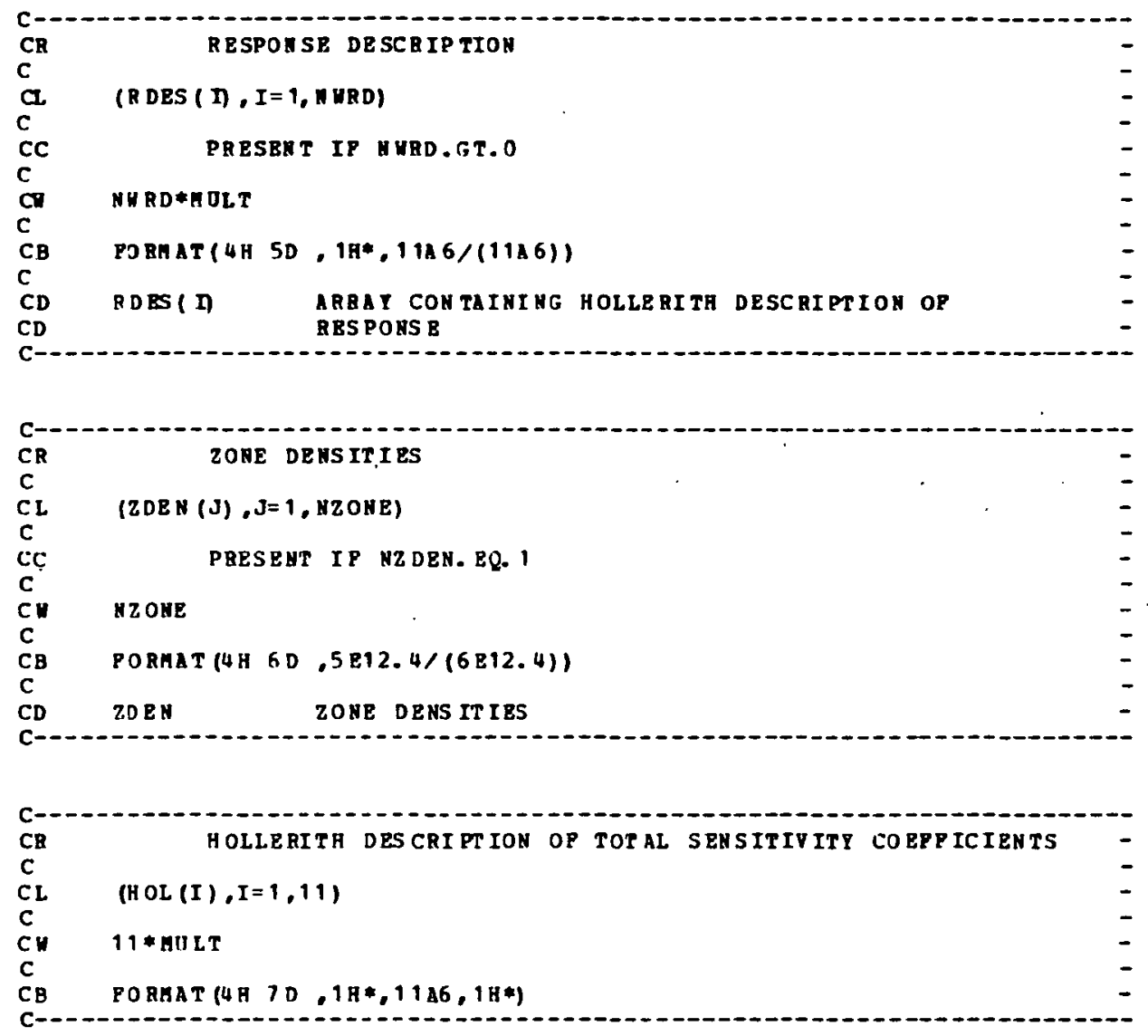





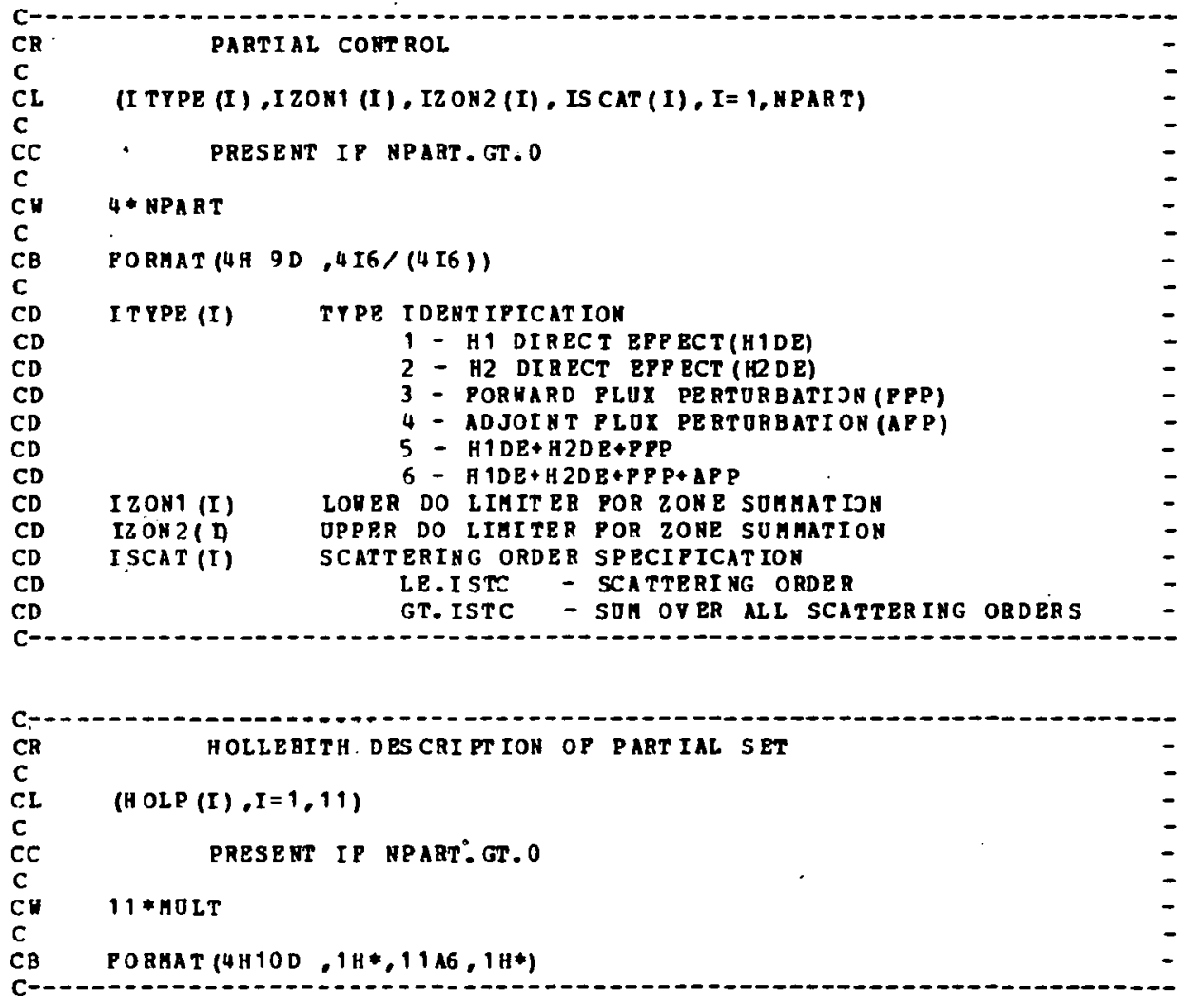

CR
$C$


$"$

THIS PAGE

WAS INTENTIONALLY

LEFT BLANK 
APPENDIX B

The FIDO Input System

The FIDO input method is especially devised to allow the entering or modifying of large data arrays with minimum effort. Special advantage is taken of patterns of repetition or symmetry wherever possible. The FIDO system was patterned by Ward Engle and Wayne Rhoades after the input method used with the FLOCO coding system at LOS Alamos, and was first applied to the DTF-II code. Since that time, numerous features requested by users have been added, a free-field option has been developed, and the application of FIDO has spread to innumerable codes.

The data are entered in units called "arrays." An array comprises a group of contiguous storage locations which are to be filled with data at one time. These arrays usually correspond on a one-to-one basis with FORTRAN arrays used in the program. A group of one or more arrays read with a single call to the FIDO package forms a "block," and a special delimiter is required to signify the end of each block. Arrays within a block may be read in any order with respect to each other, but an array belonging to one block must not be shifted to another. The same array can be entered repeatedly within the same block. For example, an array could be filled with "0" using a special option, and then a few scattered locations could be changed by reading in a new set of data for that array. If no entries to the arrays in a block are required but the condition requiring the block is met, the delimiter alone satisfies the input requirement.

Three major types of input are available: fixed-field input, freefield input, and user-field input.

Fixed Field Input - Each card is divided into six 12-column data fields, each of which is divided into three subfields. The following sketch illustrates a typical data field. The three subfields always comprise 2, 1, and 9 columns, respectively.

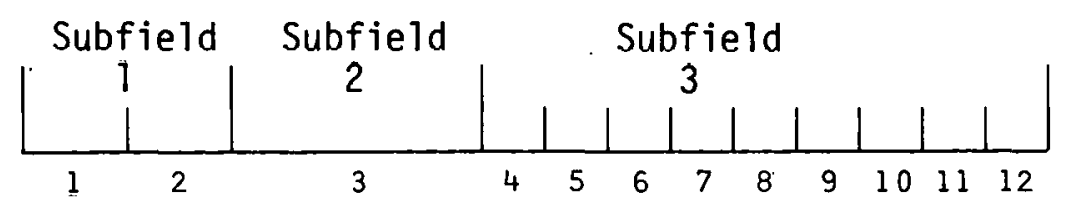


To begin the first array of a block, an array originator field is placed in any field on a card:

Subfield 1: An integer array identifier $<100$ specifying the data array to read

Subfield 2: An array-type indicator -

"\$" if the array is integer data

"*" if the array is real data

Subfield 3: Blank

Data are then place in successive fields until the required number of entries has been accounted for. A sample data sheet shown on page 19 illustrates this input.

In entering data, it is convenient to think of an "index" or "pointer" which is under control of the user, and which specifies the position in the array into which the next data entry is to go. The pointer is always positioned at array location \#l by entering the array originator field. The pointer subsequently moves according to the data operator chosen. Blank fields are a special case, in that they do not cause any data modification and do not move the pointer.

A data field has the following form:

Subfield 1: The data numerator, an integer $<100$. We refer to this entry as $\mathrm{N}_{7}$ in the following discussion.

Subfield 2: One of the special data operators listed below.

Subfield 3: A nine-character data entry, to be read in F9.0 format. It will be converted to an integer if the array is a "\$" array or if a special array operator such as "Q" is being used. Note that an exponent is permissible but not required. Likewise, a decimal is permissible but not required. If no decimal is supplied, it is assumed to be immediately to the left of the exponent, if any; and otherwise to the right of the last column. This entry is referred to as $\mathrm{N}_{3}$ in the following discussion. 
Poge

\begin{tabular}{|c|c|c|c|}
\hline & & IDENTIFICATION & REMARKS (DO NOT PUNCH) \\
\hline $1,1, \$$ & $1,1,1,1,1,1,1$ & & Begin the $1 \$$ array, fixed-field, integral \\
\hline $\begin{array}{lll}10 & 1 \\
\end{array}$ & $\begin{array}{llllllll}1 & 1 & 1 & 1 & 1 & 1 & 1 & 1\end{array}$ & & Enter 1. \\
\hline \begin{tabular}{|l|l|}
$2 B$ & $F$ \\
\end{tabular} & $1,1,1,1,1,2$ & & Fill array with 2. \\
\hline $3,2, *$ & 1,1 & & Beg in the $2^{\star}$ array, fixed-field, real. \\
\hline$\infty$ & $1, \cdot, 2,3,4,1,1,1$ & " & Enter 1.234. \\
\hline$\because 1$ & $1,2, \ldots, 3,4, \ldots,-1$ & 1,0 & $"$ \\
\hline $5_{1}-$ & $1,2,3,4,1,+, 0,2$ & & $"$ \\
\hline${ }^{1.8}, 3,-$ & $\perp, 1,1,2,3,4$ & & $"$ \\
\hline 20 & $, 1,1,1,1,7$ & & $" 7.0$ \\
\hline 37 & $\perp$ & & A blank field is always ignored. \\
\hline $\begin{array}{lll}4.0 & \mathrm{~T} \\
\end{array}$ & $1,1,1,1$ & .0 & Terminate this block. \\
\hline$" 1$ & 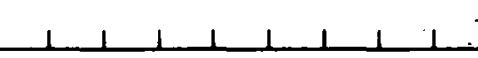 & 2,0 & No entries may follow $T$ on a card. \\
\hline$\therefore, 3, *$ & $\perp \perp \perp 1,1,1, \perp$ & & Begin $3^{*}$ array, fixed-field real. \\
\hline${ }^{18}, 9, I$ & $, 1,1,1,1,0$ & & Enter $0,1,2,3,4,5,6,7,8,9,10,10,10$. \\
\hline${ }^{38}, 3, R$ & $1,1,1,1,1,0$ & & as real numbers. \\
\hline $3, *{ }^{*} *$ & $\perp, 1,0, S_{\perp}, 1,0$, & & Repeat $3^{*}$ in free-field, skip \\
\hline 1,1, & $1,2,1,1,1,1$ & 3 & to 11th entry, correct sequence to \\
\hline (1) & 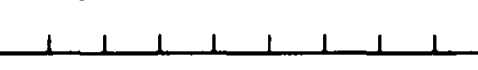 & 3,0 & $\ldots$ \\
\hline$\frac{41^{*} 1^{*}}{13}$ & $2, I, 1,1,4,1,0$, & & Begin $4^{*}$ array, free-field, real. \\
\hline $2, Q, 4$ & $1+1 \quad 1 \quad 1 \quad 1 \quad 1$ & & Enter $1,2,3,4,1,2,3,4,1,2,3,4$. \\
\hline${ }^{28}$ & $1, E_{1}, \ldots, \ldots$ & & End reading this array; remainder of array unchange \\
\hline 1 & 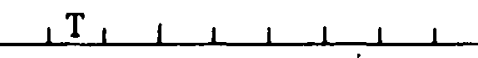 & & Terminate this block. \\
\hline 1 &  & 39 & \\
\hline$\because 1$ & 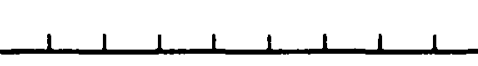 & 4,0 & \\
\hline
\end{tabular}


A list of data operators and their effect on the array being input follows:

"Blank" indicates a single entry of data. The data entry in the third subfield is entered in the location indicated by the pointer, and the pointer is advanced by one. However, an entirely blank field is ignored.

"+" or "-" indicates exponentiation. The data entry in the third field is entered and multiplied by $10^{ \pm N_{1}}$, where $N_{1}$ is the data numerator in the first subfield, given the sign indicated by the data operator itself. The pointer is advanced by one. In cases where an exponent is needed, this option allows the entering of more significant figures than the blank option. "\&" has the same effect as "+". "R" indicates that the data entry is to be repeated $N_{1}$ times. The pointer is advanced by $N_{1}$.

"I" indicates linear interpolation. The data numerator, $\mathrm{N}_{1}$, indicates the number of interpolated points to be supplied. The data entry in the third subfield is entered, followed by $N_{1}$ interpolated entries equally spaced between that value and the data entry found in the third subfield of the next non-blank field. The pointer is advanced by $\mathrm{N}_{1}+1$. The field following an "I" field is then processed normally, according to its own data operator. The "I" entry is especially valuable for specifying a spatial mesh. In "\$" arrays, interpolated values will be rounded to the nearest integer.

" $L$ " indicates logarithmic interpolation. The effect is the same as that of "I" except that the resulting data are evenly separated in log-space. This is especially convenient for specifying an energy mesh.

"Q" is used to repeat sequences of numbers. The length of the sequence is given by the third subfield, $N_{3}$. The sequence of $N_{3}$ 
entries is to be repeated $N_{1}$ times. The pointer is advanced by $N_{1} * N_{3}$. If either $N_{1}$ or $N_{3}$ is 0 , then a sequence of $N_{1}+N_{3}$ is repeated one time only, and the pointer is advanced by $N_{1}+N_{3}$. This feature is especially valuable for geometry specification.

The " $N$ " option has the same effect as "Q", except that the order of the sequence is reversed each time it is entered. This is valuable for the type of symmetry possessed by quadrature coefficients.

" $M$ " has the same effect as "N" except that the sign of each entry in the sequence is reversed each time the sequence is entered. For example, the entries:

$1232 \mathrm{M} 2$

would be equivalent to:

$\begin{array}{lllllll}1 & 2 & 3 & -3 & -2 & 2 & 3\end{array}$

This option is also useful in entering quadrature coefficients.

"Z" causes $\mathrm{N}_{1}+\mathrm{N}_{3}$ locations to be set to 0 . The pointer is advanced by $\mathrm{N}_{1}+\mathrm{N}_{3}$.

" $C$ " causes the position of the last array item entered to be printed. This is the position of the pointer, less 1 . The pointer is not moved.

"0" causes the print trigger to be changed. The trigger is originally off. Successive "0" fields turn it on and off alternately. When the trigger is on, each card image is listed as it is read.

"S" indicates that the pointer is to skip $N_{1}$ positions leaving those array positions unchanged. If the third subfield is nonblank, that data entry is entered following the skip, and the pointer is advanced by $N_{1}+1$.

"A" moves the pointer to the position $N_{3}$, specified in the third subfield. 
"F" fills the remainder of the array with the datum entered in the third subfield.

"E" skips over the remainder of the array. The array length criterion is always satisfied by an "E", no matter how many entries have been specified. No more entries to an array may be given following an "E", except that data entry may be restarted with an "A".

The reading of data to an array is terminated when a new array origin field is supplied, or when the block is terminated. If an incorrect number of positions has been filled, an error edit is given, and a flag is set which will later abort execution of the problem. FIDO then continues with the next array if an array origin was read. 0therwise, it returns control to the calling program.

A block termination consists of a field having " $T$ " in the second sub-field. All entries following " $T$ " on a card are ignored, and control is returned from FIDO to the calling program.

Comment cards can be entered within a block by placing an apostrophe (') in column 1. Then columns 2-80 will be listed, with column 2 being used for printer carriage control. Such cards have no effect on the data array or pointer.

Free-Field Input - With free-field input, data are written without tixed restrictions as to field and subfield size and positioning on the card. The options used with fixed-field input are available, al though some are slightly restricted in form. In general, fewer data cards are required for a problem, the interpreting print is easier to read, a card listing is more intelligible, the cards are easier to keypunch, and certain common keypunch errors are tolerated without affecting the problem. Data arrays using fixed- and free-field input can be intermingled at will wilhin à given bluck.

The concept of three subfields per field is still applicable to freefield input, but if no entry for a field is required, no space for it need be left. Only columns 1-72 may be used, as with fixed-field input. 
The array originator field can begin in any position. The array identifiers and type indicators are used as in fixed-field input. The type indicator is entered twice, to designate free-field input (i.e., "\$" or "**"). The blank third subfield required in fixed-field input is not required. For example: $31^{\star \star}$ indicates that array 31 , a rea $1-$ data array, will follow in free-field format.

Data fields may follow the array origin field immediately. The data field entries are identical to the fixed-field entries with the following restrictions:

(1) Any number of blanks may separate fields, but at least one blank must follow a third subfield entry if one is used.

(2) If both first and second subfield entries are used, no blanks may separate them, i.e., $24 \mathrm{~S}$, but not $24 \mathrm{~S}$.

(3) Numbers written with exponents must not have imbedded blanks, i.e., 1.0E+4, 1.0E4, 1.0+4, or even $1+4$, but not $1.0 \mathrm{E} 4$.

(4) In third-subfield data entries, only 9 digits, including the decimal but not including the exponent field, can be used, i.e., 123456.89E07, but not 123456.789E07.

(5) The $Z$ entry must be of the form: $738 Z$, not $Z 738$ or $738 Z$.

(6) The + or - data operators are not needed and are not available.

(7) The $Q, N$, and $M$ entries are restricted: $3 Q 4,1 N 4$, or $M 4$, but not $4 Q, 4 N$, or $4 M$.

User-Field Input - If the user follows the array identifier in the array originator field with the character "U" or "V", the input format is to be specified by the user. If "U" is specified, the FORTRAN FORMAT to be used must be supplied in columns 1-72 of the next card. The format must be enclosed by the usual parentheses. Then the data for the entire array must follow on successive cards. The rules of ordinary FORTRAN input as to exponents, blanks, etc., apply. If the array data do not fill the last card, the remainder must be left blank.

"V" has the same effect as "U" except that the format read in the last preceding "U" array is used. 


\section{THIS PAGE WAS INTENTIONALLY LEFT BLANK}


ORNL/TM-5946

Distribution Category UC-79d (ENDF-250)

\section{Internal Distribution}

1-3. L. S. Abbott

4. R. G. Alsmiller, Jr.

5. D. E. Bartine

6. T. J. Burns

7. G. W. Cunningham

8. G. de Saussure

9. J. D. Drischler

10. W. W. Engle, Jr.

11. G. F. Flanagan

12. W. E. Ford

13. C. Y. Fu

14. H. Goldstein (consultant)

15. N. M. Greene

16. R. Gwin

17. W. 0. Harms

18. J. D. Jenkins

19. D. C. Larson

20. R. A. Lillie

21. J. L. Lucius

22. F. C. Maienschein

23. J. H. Marable

24. F. R. Mynatt

25. E. M. Oblow

26. R. W. Peelle

27. F. G. Perey

28. R. B. Perez

29. L. M. Petrie

30. S. Raman
31. R. W. Roussin

32. RSIC

33. D. L. Selby

34. E. G. Silver

35. D. Steiner

36. M. L. Tobias

37. E. T. Tomlinson

38. D. R. Vondy

39-79. C. R. Weisbin

80. R. M. Westfall

81. L. W. Weston

82. J. E. White

83. G. E. Whitesides

84. J. B. Wright

85. R. Q. Wright

86. A. Zucker

87. P. Greebler (consultant)

88. W. W. Havens (consultant)

89. A. F. Henry (consultant)

90. R. E. Uhrig (consultant)

91-92. Central Research Library

93. ORNL Y-12 Technical Library Document Reference Section

94. Laboratory Records Department

95. Laboratory Records ORNL RC

96. ORNL Patent Office

\section{External Distribution}

97. USERDA Oak Ridge Operations, Research and Technical Support Division, P.0. Box E, Oak Ridge, TN 37830: Director

98. USERDA Oak Ridge Operations, Reactor Division, P.0. Box E, Oak Ridge, TN 37830: Director

99-100. USERDA Division of Reactor Research and Development, Washington, DC 20545: Director

101-453. For distribution as shown in TID-4500 Distribution Category, UC-79d, Liquid Metal Fast Breeder Reactor Physics (82 copies ENDF distribution) 